\title{
DESAFIOS MULTIDIMENSIONAIS PARA A COOPERAÇÃO TRANSFRONTEIRIÇA ENTRE FRANÇA E BRASIL 20 ANOS DEPOIS $(1996-2016)^{1}$
}

\author{
Gutemberg De Vilhena Silva ${ }^{2}$ \\ UNIVERSIDADE FEDERAL DO AMAPÁ \\ STÉPHANE GRANGER ${ }^{3}$ \\ UNIVERSIDADE DA GUIANA FRANCESA
}

\begin{abstract}
Resumo: Muitas são as espacialidades que se configuram hoje para o estudo das fronteiras e dos limites internacionais. Uma destas é a constituição de mecanismos de cooperação transfronteiriça endossadas pelos Estados nacionais de modo a resolver problemas em comum e, ao mesmo tempo, dinamizar a economia, proteger conjuntamente o meio ambiente e estabelecer eixos convergentes de dinâmicas sócio-culturais. O presente artigo coloca em evidência um estudo de 20 anos de cooperação entre a França (por meio da Guiana Francesa) e o Brasil - com o estado do Amapá - para a fronteira que compartilham. $\mathrm{O}$ interesse é compreender quais são os desafios que se apresentam duas décadas depois do estabelecimento de um acordo jurídico, em 1996, que permitiu a cooperação transfronteiriça (institucionalizada) entre ambos. Discutem-se os elementos de maior ressonância nas questões institucionais, geopolíticas, socioeconômicas e identitárias a partir de análise documental e trabalho de campo. As conclusões mostram que os problemas são variados, mas a migração ilegal para a Guiana Francesa, as diferentes diretrizes institucionais entre ambos e a perifericidade regional são alguns aspectos relevantes dos desafios a serem enfrentados.
\end{abstract}

Palavras-Chave: Fronteiras. Cooperação Transfronteiriça. Relações Brasil-França. Amapá. Guiana Francesa.

\footnotetext{
${ }^{1}$ Este texto contou com apoio da Coordenação de Aperfeiçoamento de Pessoal do Ensino Superior (CAPES, Brasil) por meio do projeto Pró-Defesa (Edital 031-2013).

${ }^{2}$ Docente na Universidade Federal do Amapá (UNIFAP). Coordenador do Mestrado Profissional em Estudos de Fronteira na mesma instituição. Contato: bgeografo@gmail.com.

${ }^{3}$ Docente no liceu Melkior-Garré e na Universidade da Guiana Francesa, ambos em Caiena (Guiana Francesa). Contato: granger.stephane@orange.fr.
} 


\section{BRAZIL - FRANCE CROSS-BORDER COOPERATION: MULTIDIMENSIONAL} CHALLENGES 20 YEARS LATER (1996-2016)

Abstract: Nowadays, the study of international borders is composed by many different spatialities. One of these spatialities is the establishment of cross-border cooperation mechanisms, which can be endorsed by regions or national states in order to solve common problems and, simultaneously, stimulate the economy, jointly protect the environment and establish convergent axes of socio-cultural dynamics. This article describes a study of 20 years of cooperation between a region of France (French Guiana) and the Brazilian state of Amapá. The main interest is understanding which are the challenges after 20 years of the establishment of a legal agreement that allowed institutionalization of the cooperation between these regions with a common border. The article discusses the most important elements of resonance regarding the institutional issues, geopolitical, socioeconomic and identity based on document analysis and field work. Conclusions indicate diverse challenges to be faced, including these main issues: illegal immigration to French Guiana and its regional peripherality, as well as, different institutional guidelines and socio-economic contrasts between the French and the Brazilian regions.

Keywords: Borders. Cross-Border Cooperation. Brazil-France relations. Amapá. French Guiana.

\section{Introdução}

Existe desde 1996 uma cooperação transfronteiriça atípica na América do Sul. Referimo-nos a ações colaborativas em uma zona de fronteira que une fisicamente um território francês/europeu com um país sul-americano. Localizada a $7.100 \mathrm{~km}$ de Paris, já em território sul-americano (Mapa 1), a Guiana Francesa possui 730 km de contato territorial com o estado do Amapá (Brasil), sendo esta a maior das fronteiras terrestres da França no mundo. Além disso, aquele território francês é uma das nove Regiões Ultraperiféricas (RUP's) ${ }^{4}$ da União Europeia (UE) e parte integrante da República Francesa desde 1946 quando deixou o estatuto colonial para se tornar Departamento de Ultramar. Em 2016, ou seja, 70 anos depois, a Guiana Francesa tornou-se uma Coletividade Territorial de Ultramar, o que simplificou a sua administração local ${ }^{5}$.

Os contornos fronteiriços deste ultramar francês com o Brasil resultam de uma série de litígios ao longo de pelo menos três séculos. O ano de 1900 é particularmente singular e relevante para a geopolítica das fronteiras dos dois países,

\footnotetext{
${ }^{4}$ As Regiões Ultraperiféricas (RUP's) são territórios distantes fisicamente da UE, mas dela pertencentes. Possuem dispositivos institucionais e operacionais específicos estabelecidos no Tratado de Maastricht (Arts. 349 e 355) e outras normativas elaboradas e implementadas em seguida para deixar claro o papel por elas desempenhado na UE, caso do Tratado de Amsterdam (Art. 299, $\mathbf{n}^{\mathbf{0} 2}$ ) e dos princípios de Caiena (ver SILVA et al. 2016). Constituem as RUP's três regiões francesas do ultramar (Guadalupe, Reunião e Mayotte), três coletividades de ultramar e também francesas (Guiana Francesa, Martinica e SaintMartin); duas regiões autônomas portuguesas (Arquipélago de Açores e Madeira); e uma comunidade autônoma espanhola (Ilhas Canárias).

${ }^{5}$ Os departamentos, regiões e coletividades francesas de ultramar desfrutam da total igualdade jurídica com a França Hexagonal, ao contrário dos "países de ultramar" franceses, como a Polinésia Francesa e a Nova Caledônia, que têm um estatuto de autonomia alargada dentro da República Francesa mas não fazem parte da UE.
} 
pois marca a resolução definitiva das disputas pelo contestado franco-brasileiro ${ }^{6}$. Já com sua díade devidamente sedimentada, de lá para cá transcorreu mais de um século de diplomacia franco-brasileira (1900-2016) e mesmo assim poucas ações de colaboração entre ambos tiveram como alvo a zona fronteiriça que compartilham.

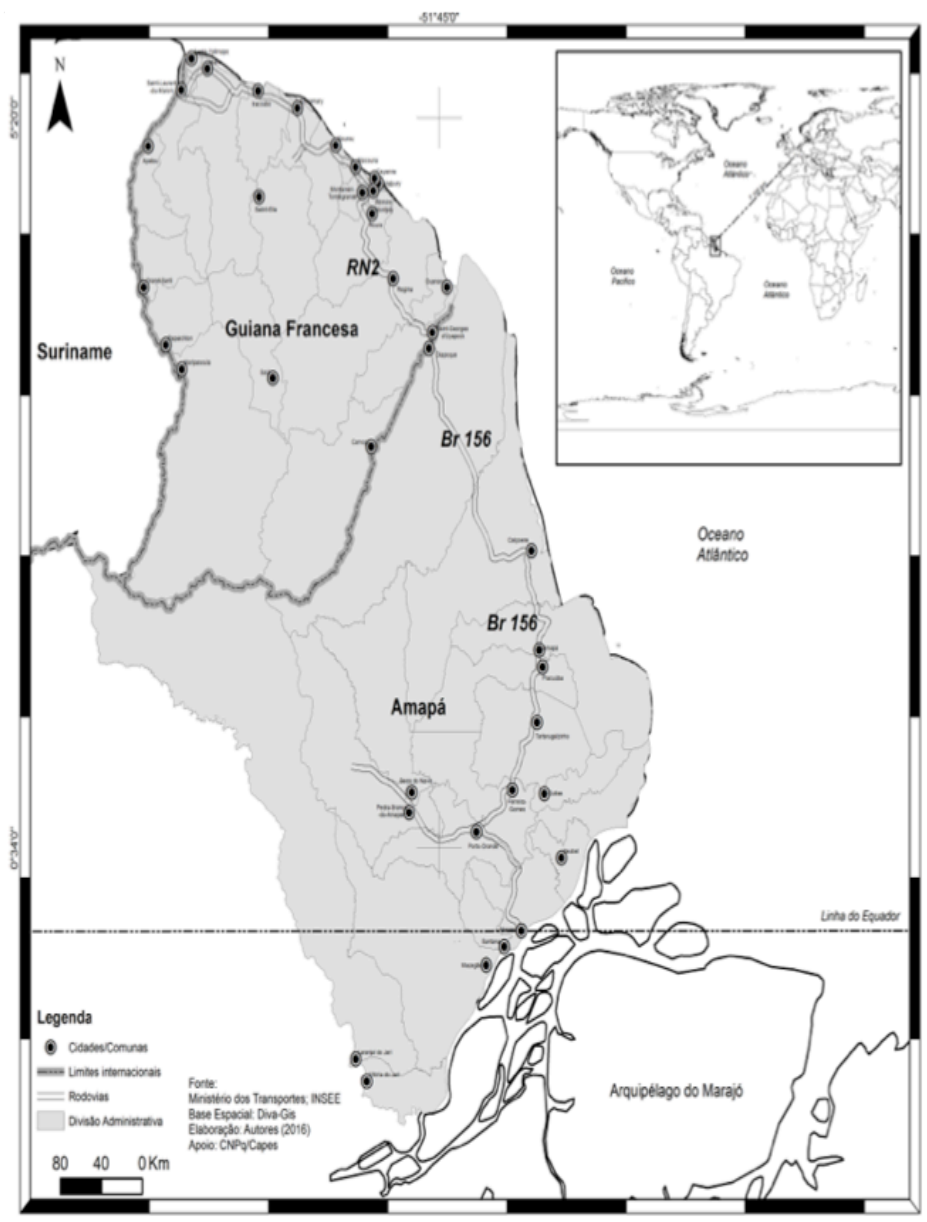

Mapa 1: A fronteira franco-brasileira

${ }^{6}$ Expressão que se refere às disputas territoriais entre França e Brasil no norte da América do Sul (Ver ARAÚJO JORGE, 1999; GRANGER, 2012). 
No percurso histórico, ocorreram momentos de muita tensão naquela fronteira, inclusive conflitos armados entre os séculos XVI e XIX ${ }^{7}$; seguidos por temporalidades e espacialidades de auto isolamento e, no início dos anos 1980, quando ambos promoveram uma reunião binacional para tratar da questão migratória, reflexo da necessidade de mão-de-obra para construção da base espacial de Kourou $^{8}$, houve paulatinamente uma reversão das suas relações binacionais, sacramentadas de maneira pragmática e objetiva nos anos 1990 quando foram promovidos acordos de cooperação transfronteiriça.

A reversão se tornou perene com mudanças estruturais e técnico-operacionais implementadas a partir de 1996 com a publicação do acordo-quadro francobrasileiro para ações transfronteiriças. Este dispositivo administrativo, através de seu artigo $6^{\circ}$, fez menção pela primeira vez ao potencial para colaboração na fronteira compartilhada pelos dois países, e que - por isso - seria estrategicamente relevante um projeto de cooperação transfronteiriço convalidado pelos poderes centrais de ambos. Aquele dispositivo foi seguido por documento assinado no mesmo ano pelos executivos regionais do Amapá e da Guiana Francesa reforçando a convergência de interesses na aproximação. Inclusive, o diálogo profícuo entre os executivos locais foi um determinante nesta nova página nas relações bilaterais para a fronteira que compartilham. Evidentemente que o cenário de regionalismo aberto 9 europeu e sul-americano influenciou tal aproximação.

Uma ilustração simbólica das intenções de cooperação transfronteiriça na fronteira franco-brasileira ocorreu em 1997. Naquele ano, reuniram-se na cidade franco-guianense de Saint-Georges o então presidente brasileiro Fernando Henrique Cardoso com o presidente francês à época Jacques Chirac. Aquele gesto foi repetido, na mesma cidade, por Luiz Inácio Lula da Silva e Nicolas Sarkozy, em 2008 (Foto 1). No primeiro encontro, em 1997, houve a decisão da construção de uma ponte binacional ligando a Guiana Francesa e o Amapá a partir de demanda apresentada pelos gestores locais à época, Antoine Karam e João Capiberibe respectivamente. Os anos seguintes testemunharam reuniões das mais variadas com

\footnotetext{
${ }^{7}$ Por exemplo, em maio de 1895 ocorreu no contestado um sangrento confronto armado entre brasileiros e franceses, seguido de um massacre da população civil da Vila Amapá por tropas de infantaria da marinha da França, enviadas de Caiena. Sobre tais conflitos ver Reis (1993); Araújo Jorge (1999); Silva e Rückert (2009); Boudoux d'Hautefeuille (2012) e Granger (2012).

${ }^{8}$ A base de lançamento em Kourou, na Guiana Francesa, está sob a égide da França, mesmo com a emergência de uma estrutura espacial à dimensão europeia, que tomou forma ainda na década de 1950. A Agência Espacial Europeia (European Spatial Agency - ESA), cuida dos lançamentos desde sua fundação, em 1975. Entre as décadas de 1960 e 1980, momento da estruturação física da base para os lançadores, houve a atração de mão-de-obra dos vizinhos, principalmente brasileira, deslocando-se da Europa somente os profissionais especializados em alta tecnologia. Em decorrência das minas auríferas e da emergência do Euro associados à seguridade francesa - a imigração (ilegal) na Guiana Francesa se tornou um problema. Trataremos deste problema na sequência deste texto.

${ }^{9}$ Uma boa leitura sobre o novo regionalismo ou regionalismo aberto pode ser feita em Heinonen (2006).
} 
a ponte binacional sendo direta ou indiretamente um tema recorrente, inclusive na reunião diplomática entre Lula e Sarkozy, em 2008.
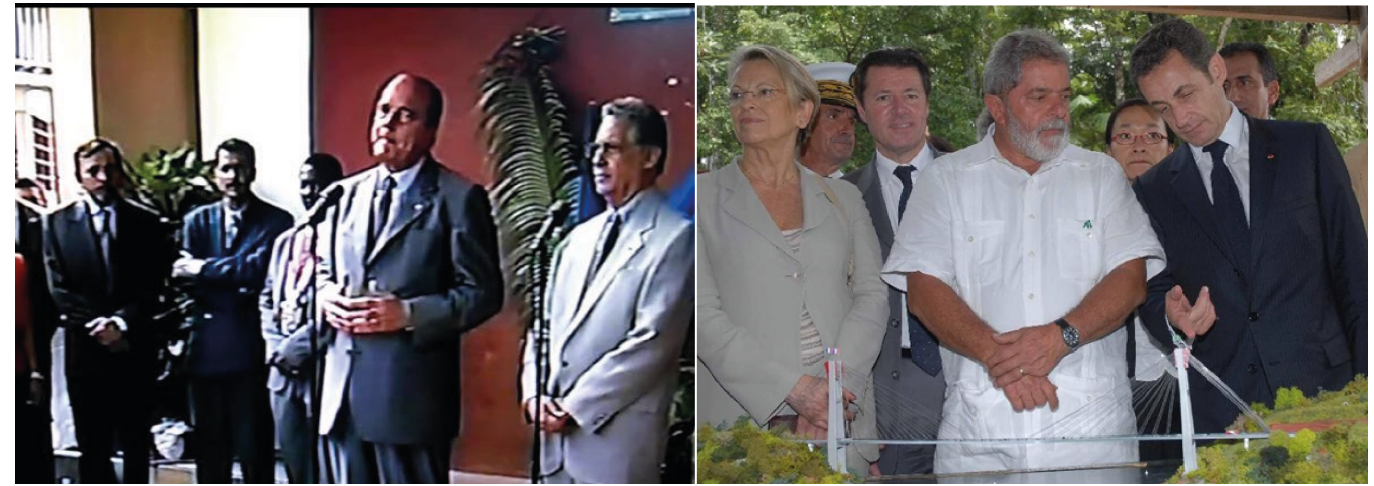

Foto 1: Encontro de presidentes de Brasil e França na fronteira franco-brasileira (1997 e 2008)

Fontes: Adaptado de: Acervo pessoal de João Capiberibe: http://www1.rfi.fr/actubr/articles/098/article_11964.asp

No ano de 2016, o acordo-quadro completou 20 anos (1996-2016). Então, tomando por base esses dois decênios, interrogamos- nos: quais são os desafios multitemáticos que se apresentam para a evolução técnico-operacional da cooperação transfronteiriça franco-brasileira? Discutiremos aqui os elementos de maior ressonância nas questões institucionais, geopolíticas, socioeconômicas e identitárias, embora saibamos que outras temáticas (como ambiental, sanitária, educacional, agrícola, da segurança, etc.), sejam igualmente relevantes para uma contextualização ampla e densa dos vários desafios que tal fronteira enfrenta. Para desenvolver nossa proposta de maneira clara, objetiva e elucidativa, considerando as diversas variáveis para análise, recorremos à análise documental e ao trabalho de campo em termos operacionais, este último realizado em vários momentos nos últimos 10 anos.

\section{Desafios da cooperação transfronteiriça Brasil-Guiana Francesa}

A cooperação transfronteiriça, tal como definida pela convenção-quadro de Madri em 1980, é uma cooperação bilateral, trilateral ou multilateral entre autarquias locais e regionais (podendo ainda envolver atores da esfera semi-pública ou privada) de regiões limítrofes, ou separadas por mar, e que tem por principal objetivo a aproximação multitemática de regiões separadas por fronteiras nacionais que enfrentam problemas comuns e carecem de soluções igualmente comuns (UNION EUROPEENNE, 2002, COMMISSION EUROPEENNE, 2015). Este é o caso da fronteira entre França e Brasil no norte da América do Sul. 
A reforma territorial da França (leis de Descentralização), em 1982, quase quatro décadas após o estabelecimento da Guiana Francesa como departamento ultramarino da França, ocorrido em 1946, concedeu mais poderes às suas coletividades locais: communes (municípios), départements e Régions. Em adição, criou para os departamentos ultramarinos (départements d'outre-mer) uma hierarquia administrativa com mais poderes em relação ao seu planejamento territorial que até então não existia, as chamadas Régions d'Outre-mer.

Por outro lado, em 1988 a elaboração da nova constituição do Brasil (da "Nova República") transformava os últimos territórios federais ${ }^{10}$ deste país, dentre os quais o Amapá, em estados da federação brasileira, com eleições para governador e assembleia estadual. O Amapá conseguiu em 1988 - como a Guiana Francesa alguns anos antes (quando se tornou Région d'Outre-mer), um estatuto mais autônomo. Essas alterações estatutárias facilitaram a aproximação institucional entre ambos naquela década, embora o adensamento das interações transfronteiriças não estivesse na pauta da diplomacia franco-brasileira em primeiro plano por diversos motivos, alguns explicados no texto.

O recém-criado estado do Amapá, por exemplo, tinha ainda muitos desafios federativos para dar atenção a partir de sua estadualização ${ }^{11}$. Precisava acima de tudo criar e fortalecer instituições locais relevantes, mas até então inexistentes ${ }^{12}$, de tal forma que os assuntos internacionais com o vizinho francês foram relegados a um segundo plano do ponto de vista político-institucional. A Guiana Francesa, por seu turno, já começava a dar sinais de saturação com a migração clandestina brasileira ainda na década de 1980, resultando em encontro transfronteiriço entre autoridades nacionais e locais de ambos os países, em 1983, para resolução conjunta do problema (GRANGER, 2016). Além disso, o padrão estatutário da Guiana Francesa, ainda sem sintonia com seu ambiente regional, colaborou para as dificuldades na aproximação multitemática para cooperação transfronteiriça com o Brasil.

A aproximação que permitiu a fase decisiva da cooperação transfronteiriça franco-brasileira foi permitida pelo ativismo de uma nova geração de políticos eleitos na década de 1990 tanto no Amapá quanto na Guiana Francesa (GRANGER, 2012). O apoio foi dado, tanto por um lado quanto pelo outro, de maneira muito cautelosa e lenta, em razão de quase um século de ignorância e isolamento. Por tais

\footnotetext{
${ }^{10}$ Com a resolução do contestado franco-brasileiro, o Amapá passou a ser parte integrante do estado do Pará de 1900 até 1943 quando, por diversas razões - notadamente geopolíticas- se transforma em Território Federal do Amapá (TFA). Sobre a questão ver Porto (2003; 2007).

${ }^{11}$ Sobre as transformações econômicas e institucionais do Amapá após a estadualização, ver Porto (2003).

${ }^{12}$ Com a Constituição de 1988, o Amapá adquiriu autonomia e capacidade de se auto organizar; elaborar sua própria constituição; escolher seus representantes do executivo e legislativo, estadual e federal; criar sua Assembleia Legislativa; e fazer seus próprios planos de desenvolvimento (PORTO, 2007, p.13). No caso da Guiana Francesa, o Conselho regional desde as leis de decentralização de 1982, cuida principalmente do desenvolvimento econômico, do planejamento territorial e da cooperação regional.
} 
motivos, apesar de França e Brasil terem firmado quase uma centena de acordos bilaterais no século XX, e de terem uma extensa fronteira política, até 1995 somente três desses acordos tiveram um efeito direto sobre a fronteira e, ainda assim, o assunto em pauta foi tão-somente o estabelecimento técnico dos limites internacionais entre ambos os países (SILVA, 2013a).

A partir de 1996, a fronteira franco-brasileira ganhou nova tonalidade com o acordo-quadro, embora de maneira lenta e gradativa como já mencionado. Propostas de cooperação institucionalizada para as áreas de segurança, saúde, transportes, agricultura, língua, educação, economia e tantas outras se tornaram assuntos de uma agenda perene. É ponderável que as interações em zonas de fronteira dependem de muitos fatores para lhes dar impulso. Entre os condicionantes que favorecem tais processos destacamos: a) capacidade governamental de articulação político-administrativa binacional, de modo que instrumentos compartilhados sejam criados para resolver problemas comuns nas diretrizes da cooperação; b) comprometimento político de ambos os lados com a presença de um marco de relações permanentes e contínuas; c) ajustamento de parâmetros econômicos que possam minimamente resolver a distorção de mercados muito diferentes em termos de renda, capital financeiro e mercado consumidor; d) diálogo constante sobre problemas que se apresentam por muito tempo, com dificuldades frequentes para a sua resolução e que comprometem significativamente um dos lados da fronteira; e) convergência geopolítica de interesses em diferentes níveis de gestão e poder; e, por fim, f) a criação de uma identidade coletiva fortalecedora de laços de cooperação regional.

Para tratar de tais condicionantes como desafios a serem superados para o desenvolvimento e fortalecimento de estruturas sólidas à cooperação transfronteiriça entre Guiana Francesa e Amapá, o presente artigo foi organizado em quatro grandes eixos tradados a seguir, sendo elas: desafios institucionais, socio-econômicos, geopolíticos e identitários.

\section{Desafios institucionais}

Este eixo examina os desdobramentos implicados nas Comissões Mistas Transfronteiriças (CMT's) e a capacidade governamental como vértice central no desafio institucional. As CMT's, constituídas por representantes dos poderes políticos nacionais e estaduais, representam o principal mecanismo de reflexão, submissão e aprovação de propostas de cooperação transfronteiriça entre França e Brasil. Constatamos em análise documental que as primeiras quatro CMT's (1997, 1999, 2002, 2008) serviram para montar propostas que pudessem ser viabilizadas em médio e longo prazo, a exemplo da pavimentação das rodovias que conectam os dois lados (RN2 e BR156), dá construção da ponte binacional fronteiriça, de escolas 
de língua nas capitais do Amapá e da Guiana Francesa, entre outras. Nas comissões seguintes, fica evidente um reforço das negociações em temáticas específicas (ponte binacional, pavimentação da BR 156, etc.) e o surgimento tênue de novas oportunidades de cooperação transfronteiriça. A última CMT, realizada em dezembro de 2016, sinalizou uma data para abertura provisória da ponte sobre o rio Oiapoque, como também permitiu ou confirmou muitos acordos e parcerias em setores diversos como a segurança civil, a educação universitária, a cooperação militar e policial, o regime dos vistos e vários outros.

Em linhas gerais, a capacidade governamental de articulação políticoadministrativa é base nos desafios institucionais. Ela está sujeita ao menos a dois tipos de condicionantes. Os primeiros dizem respeito ao marco jurídico, ao federalismo, à descentralização e às relações intergovernamentais. Na outra ponta estão as capacidades de condução, consenso e articulação com os distintos atores; a estrutura administrativa, os instrumentos técnicos, as finanças públicas e a eficácia da gestão e da regulamentação interna.

No caso franco-guiano-brasileiro, a capacidade governamental das políticas territoriais demonstram baixos critérios de eficácia, eficiência e efetividade. Por exemplo, mesmo com mais de 60 propostas submetidas nas dez comissões mistas já realizadas entre 1997 e 2016, poucas ações e estruturas fortalecedoras foram efetivamente postas em prática. Podemos, no entanto, destacar êxitos na cooperação militar e policial (como participação de oficiais brasileiros nas instâncias francesas) e no meio técnico-científico-informacional com a cobertura do Amapá com fibra ótica, fornecida por empresa franco-guianense, a Guyacom. Ainda assim, as que foram efetivadas, apresentam dificuldades de operacionalidade, em razão do diminuto empenho administrativo e carência de recursos financeiros.

Outra ponderação importante a ser feita é que alguns sistemas legislativos nacionais são mais liberais que outros no que se refere ao reconhecimento das administrações locais ou regionais para participação direta em iniciativas de cooperação transfronteiriça e, por conseguinte, na gestão de programas. Este fator é significativo no caso da Guiana Francesa, já que a maior parte das decisões programáticas advém de Paris, ou seja, de um contexto europeu que pouco tem a ver com o ambiente regional sul-americano, mas cujos pressupostos determinam as diretrizes e as ações a serem efetivadas, ainda mais quando o assunto é de interesse econômico e/ou geopolítico, como migração, exploração de recursos naturais estratégicos, a exemplo do ouro, e comércio transfronteiriço. O fator mencionado cria dificuldades significativas no estabelecimento de instrumentos legais convergentes para a zona de fronteira. As complicações para uma legislação transfronteiriça de circulação de veículos e de mercadorias entre os dois lados é o exemplo mais emblemático. 


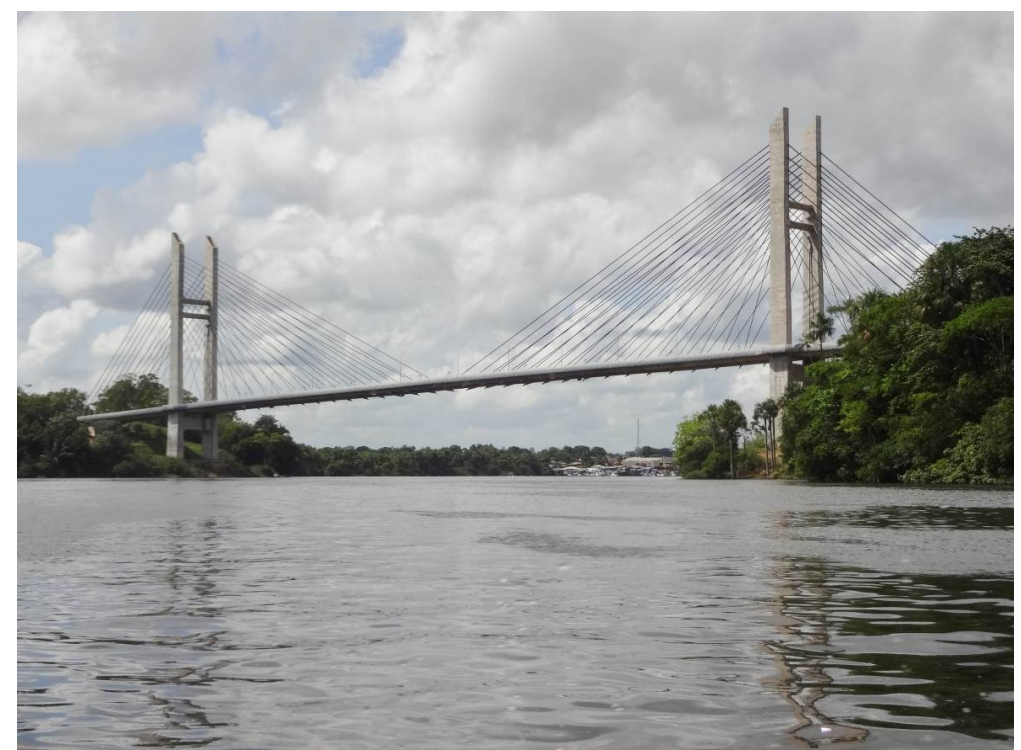

Foto 2: Ponte binacional sobre o Rio Oiapoque

Fonte: Stéphane Granger, trabalho de campo (2013)

Com efeito, a fragilidade na fiscalização de entrada-saída de mercadorias repercute de maneira generalizada. Ocorreram evoluções nas diretrizes gerais para circulação pela ponte binacional franco-brasileira, que deverá funcionar parcialmente em 2017, apesar de ter sido concluída em 2011 (Foto 2). Contudo, ainda há diversos problemas para circulação que precisam ser resolvidos, a exemplo do ajuste do preço a ser pago no seguro para trânsito de carros brasileiros na Guiana Francesa, considerado elevado para o padrão regional. Essa regulamentação, quando devidamente ajustada, contribuirá para institucionalizar a geografia da circulação transfronteiriça.

\section{Desafios socioeconômicos}

Dois núcleos centrais são tratados aqui. Em primeiro lugar, a geografia econômica do espaço vivido da fronteira franco-brasileira, que é um aspecto relevante na cooperação regional, mas com pouca voz nas discussões bilaterais. E, em segundo lugar, um dos maiores desafios para o adensamento da cooperação, a migração ilegal de brasileiros para aquela coletividade territorial francesa.

A Guiana Francesa, em razão da sua condição singular na América do Sul, beneficia-se de fundos comunitários europeus dedicados à cooperação econômica regional (p. ex. o POAmazônia/PCIA analisado no desafio geopolítico). Mesmo assim, as trocas comerciais com seus vizinhos têm permanecido abaixo de $15 \% \mathrm{em}$ média (INSEE, 2011ab). O fortalecimento do comércio com Brasil e Suriname é um 
desafio significativo para a Guiana Francesa, ainda mais quando se trata do comércio transfronteiriço, um fenômeno difícil de controlar e mensurar. No caso franco-brasileiro, o comércio transfronteiriço é- em geral - informal e muitas vezes ilegal. No primeiro caso, porque ainda não há diretrizes claras sobre importaçãoexportação por meio da fronteira, já comentado anteriormente no desafio institucional. Todos os dias algumas centenas de pessoas transportam mercadorias entre as cidades e vilas às margens do rio Oiapoque (Foto 3).

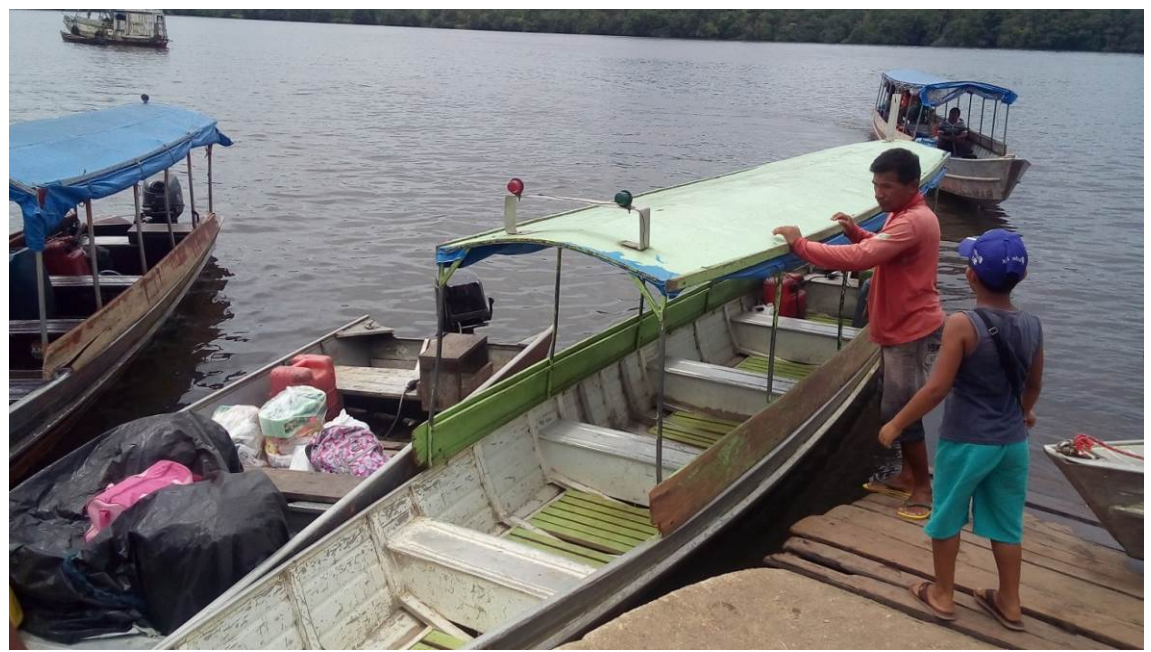

Foto 3: Exemplo de circulação de mercadorias pelo rio Oiapoque

Fonte: Gutemberg Silva, Trabalho de campo (2016)

Nessa geografia da circulação transfronteiriça, existem alguns entrepostos importantes na relação produção-circulação-consumo. Na cidade de São Paulo, os comerciantes de Oiapoque compram boa parte dos produtos eletrônicos (principalmente celulares), da mesma forma que Fortaleza se destaca como principal cidade para compra de vestuário. Estes dois tipos de produtos são as principais tipos de mercadorias vendidos na fronteira (SILVA, 2016).

Após a mercadoria passar por Macapá, capital do Amapá, os produtos são deslocados por cerca de $600 \mathrm{~km}$ até chegar a Oiapoque, destino inicial da venda. Esse deslocamento ocorre pela rodovia BR 156 (Mapa 1), via historicamente problemática pelas péssimas condições de tráfego em muitos trechos. Essa dificuldade na logística aumenta o preço dos produtos que serão vendidos em Oiapoque, a exemplo do gás de cozinha, do diesel que abastecerá as pequenas centrais energéticas da cidade e, evidentemente, dos principais produtos da pauta, vestuário e eletrônicos.

Ao chegar a Oiapoque, boa parte da mercadoria é vendida nos vários estabelecimentos localizados às margens do rio Oiapoque, seja para moradores 
locais ou para turistas que circulam pela fronteira; e outra parte suprirá a demanda de pequenas comunidades ribeirinhas, como é o caso de Vila Brasil e Vila Sikini (Ilha Bela), ambas do lado brasileiro.

Do lado francês, há alguns poucos estabelecimentos comerciais que suprem a demanda local, até mesmo pela população reduzida de Saint-Georges, Camopi e Ouanary, os três municípios (communes) franceses da fronteira (Mapa 1) que, juntos, totalizam cerca de 6 mil hab. ao passo que no lado brasileiro a população gire em torno de 30 mil hab. (INSEE, 2012; SILVA, 2013ab). Na Guiana Francesa, os produtos são oriundos da França metropolitana ou da UE de um modo geral, mas chegam às cidades fronteiriças mencionadas a partir de Caiena (SILVA, 2016). A força da moeda europeia, o Euro, frente à brasileira, o Real, motiva e potencializa a proliferação de pontos comerciais do lado brasileiro. Esta característica é perceptível em todo o curso da extensa fronteira do Brasil, mas com um comportamento inverso, ou seja, de brasileiros atravessando para realizar compras nos países vizinhos, embora o tipo de produto comercializado varie caso-a-caso (ver BRASIL, 2005; 2016).

O segundo tipo da geografia da circulação de mercadorias mencionado, o ilegal, ocorre em razão de alguns produtos terem sua comercialização proibida em um dos países. Por exemplo, as normas europeias para aquisição de alimentos interditam a entrada de frango e carne bovina brasileira por meio da fronteira. Há uma fiscalização sistemática entre Saint-Georges e Cayenne para diminuir ao máximo essa circulação, que é muito frequente, em razão do preço ser muito atraente. No sentido inverso, há problemas com aquisição de remédios abortivos, algumas armas e eletrodomésticos (SILVA, 2016). A inauguração de um posto de fiscalização rodoviária em Oiapoque há alguns anos, diminuiu o fluxo de mercadorias irregulares entre Oiapoque e Macapá e também elucidou um pouco mais a geografia da circulação de ilícitos.

As diferenças sociais entre Amapá e Guiana Francesa geram outro tipo de circulação transfronteiriça: os fluxos migratórios ilegais para este último. Por ser parte integrante da República Francesa, a Guiana Francesa desfruta de um alto padrão salarial para o perfil regional e uma eficiente seguridade social (GRANGER, 2012), portanto atrai muitos migrantes, sobretudo de três países: Suriname, Brasil e Haiti (INSEE, 2012). Estes países, mesmo com variações anuais, destacaram-se ao longo das três últimas décadas. No início dos anos 1980, a participação dos imigrantes na população da Guiana Francesa já era superior a $25 \%$ e hoje orbita em torno de $40 \%$ do total (INSEE, 2011b).

Esta coletividade ultramarina se sobressai em qualidade de vida no seu ambiente geográfico imediato: os países da região mostram um Índice de Desenvolvimento Humano (IDH) bem abaixo do nível franco-guianense, incluindo o Brasil. Conforme Granger (2012) e Silva (2013), essas diferenças nos padrões de vida colaboram para os dados significativos de migrantes na Guiana Francesa. Aliás, a cidade de 
Oiapoque também é a nova porta de entrada de haitianos e dominicanos, como também de africanos e de pessoas oriundas do Oriente-Médio, cujo objetivo principal é conseguir o estatuto de refugiado político na Guiana Francesa (GRANGER, 2016). Aliás, essa preocupação de diminuir os fluxos migratórios em direção às regiões europeias, como a Guiana Francesa, é a origem de alguns acordos de cooperação transfronteiriça entre a UE e regiões vizinhas pouco desenvolvidas, como veremos mais tarde.

Para controlar a pressão migratória na Guiana Francesa, forte demais por causa da fraca população nativa e em razão da alta taxa de desemprego (INSEE, 2011b), o governo francês implantou barreiras no interior de seu território, como os postos policiais de Iracoubo e Régina à beira do rio Approuague - um dispositivo excepcional de controle francês, não aplicado em nenhum outro território ultramarino e nem na França Hexagonal. O controle policial na cidade de Régina (Mapa 1), que sucedeu o controle feito por anos em Bélizon (Foto 4) - é um posto militar francês - quase equidistante entre Caiena e Saint-Georges, que faz a fiscalização e o controle de entrada e saída no leste da Guiana Francesa.

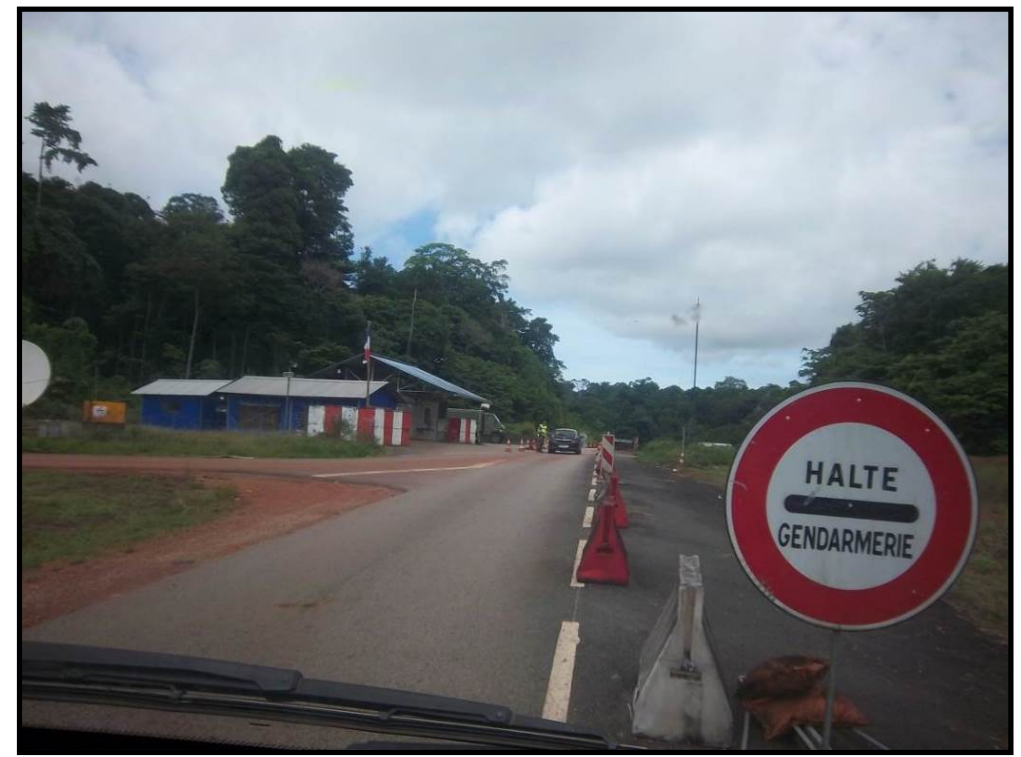

Foto 4: Antigo posto de Bélizon (Controle Policial Francês)

Fonte: Gutemberg Silva, Trabalho de Campo (2011)

Pensando na frequência da migração ilegal de brasileiros para a Guiana Francesa, algumas medidas foram adotadas mesmo com dificuldades para permanecer ativas. Dentre elas, é relevante destacar a criação de uma carta de circulação transfronteiriça, um posto consular em Saint-Georges, a Casa do migrante e o Conselho do Rio (SILVA, 2013ab; 2016). 
A pressão migratória, aliás, justifica para os franceses a exigência de cobrança de visto aos brasileiros que desejam entrar na Guiana Francesa, embora esse visto exigido não seja necessário para brasileiros em nenhum outro território francês. Tal questão ainda hoje é fator de constrangimentos diplomáticos entre a França e o Brasil e atrapalha a evolução da cooperação transfronteiriça. Esse tema foi muito discutido na última CMT, em 2016. Naquele momento, as autoridades francesas se comprometeram em simplificar as exigências para turistas, estudantes e pesquisadores brasileiros a partir de 2017, o que é um avanço e, portanto, colabora no fortalecimento da cooperação.

\section{Desafios geopolíticos}

Este tópico examina pontos de convergência-divergência entre UE com os mecanismos recentes de integração física sul-americana, e as tentativas dos atores locais em fortalecer seu papel nas decisões e ações na cooperação transfronteiriça. As formulações estratégicas da política externa da França e do Brasil diferem em termos de concepção e operacionalidade. A primeira adota as diretrizes estabelecidas no bloco europeu, isto quer dizer que suas fronteiras são pensadas de maneira una e integrada, inseridas dentro de um conjunto supranacional, a UE. No Brasil as diretrizes são formuladas caso-a-caso para sua vasta fronteira terrestre (BRASIL, 2005; 2016; SILVA, 2013ab). Derivado deste desafio, outros complicadores emergiram em escala regional-local, principalmente no que diz respeito à participação política do Amapá e da Guiana Francesa nas principais decisões de quanto, quando, por que e onde investir na cooperação transfronteiriça entre França e Brasil.

A Coletividade territorial de Guiana francesa apresenta a particularidade de figurar nos seguintes recortes geopolíticos: o amazônico/sul-americano em termos de biodiversidade e localização geográfica; o espaço europeu, no que se refere aos aspectos administrativos continentais, com características específicas que compartilha com outras RUP's (p. ex. o afastamento do continente europeu, do qual possui forte dependência econômica e comercial); e, por fim, o espaço caribenho no qual a Guiana Francesa também pertence histórica e culturalmente ${ }^{13}$ (GRANGER, 2008; TAGLIONI \& CRUSE, 2011; SILVA et al., 2016).

Em 2007, a UE criou - por meio do INTERREG IV-, o Programa Operacional Amazônia (POAmazônia), programa comunitário europeu orientado para inserção regional da Guiana Francesa. Desde os anos 1990, a UE tem incentivado a política de Coesão Europeia, ou seja, estímulos à cooperação transfronteiriça entre os signatários ao bloco. Como ferramenta principal da política europeia de coesão, as

\footnotetext{
${ }^{13}$ Aliás, o governo estadual da Guiana Francesa, como os da Martinica e de Guadalupe, representa a França na Associação dos Estados do Caribe (AEC).
} 
iniciativas INTERREG tornaram-se relevantes instrumentos de financiamento. Desde o início de tais iniciativas, cinco períodos de programação se sucederam ${ }^{14}$, com o último ainda ativo. A Guiana Francesa somente começou a ser envolvida a partir do INTERREG III, mas foi nos seguintes que esta Coletividade de Ultramar obteve um investimento direcionado à sua inserção regional na América do Sul.

O Programa Operacional Amazônia (POAmazônia), criado no INTERREG IV, permitiu a convergência entre objetivos europeus, da Guiana Francesa e de seus vizinhos sul-americanos, embora o volume financeiro europeu investido ${ }^{15}$ superasse $50 \%$ do total, até porque é uma iniciativa europeia mesmo que encontre correspondência de interesses com os países vizinhos à Guiana Francesa. A primeira edição do programa (2007-2013) financiou 19 projetos envolvendo o Suriname e três estados amazônicos brasileiros: Amapá, Pará e Amazonas (SILVA et al. 2016). Encontra-se em curso a Versão II do POAmazônia (2014-2020), criado no INTERREG V, e agora chamado PCIA (Programa de Cooperação Interreg Amazônia). Uma novidade é que o INTERREG agora vigente abrange também a República Cooperativa da Guiana, uma novidade em relação às ações da Versão I do programa.

Essa política de cooperação transfronteiriça por parte da UE também se deve a uma vontade de diminuir, pela ajuda ao desenvovimento regional, os fluxos migratórios oriundos de regiões mais pobres vizinhas da UE, mas com as quais essa está querendo se aproximar. Assim, tal política também existe, além do Caribe (INTERREG III) e da Amazônia (INTERREG IV e V) com países dos Balcãs e do Marrocos ${ }^{16}$ (COMMISSION EUROPENNE, 2015).

Para as autoridades da Guiana Francesa, iniciativas como o POAmazônia/PCIA deveriam gerar pelo menos dois resultados concretos que vem ocorrendo lentamente: em primeiro lugar, o fortalecimento de sua inserção na América do Sul, que é historicamente frágil em função do estatuto político diferenciado daquela Coletividade de Ultramar; e, em segundo, peso político mais relevante para a classe política local face ao poder central francês. Além disso, para a população de um modo geral, o financiamento deveria contribuir de maneira proativa para o desenvolvimento regional pautado nos interesses locais, o que não ocorre regularmente. Dessa forma, a confluência da Europa com a América do Sul continua sendo periférica para a população autóctone e frequentemente descuidada pelo poder central, marcas de uma perifericidade ainda acentuada.

\footnotetext{
${ }^{14}$ São eles: INTERREG I (1990-1993); INTERREG II (1994-1999); INTERREG III (2000-2006); INTERREG IV (2007-2013) e INTERREG V (2014-2020).

${ }^{15}$ O Fundo Europeu de Desenvolvimento (FEDER) investiu 20, 6 milhões de euros contra 10,9 milhões de euros de contrapartida de outros 2 países (Brasil e Suriname).

${ }^{16}$ Em território marroquino encontram-se encravadas duas cidades espanholas e portanto europeias : Ceuta e Melilla, alvos de enormes fluxos migratórios.
} 
$\mathrm{Na}$ América do Sul, o programa que mais implicou suas fronteiras nas duas últimas décadas foi a iniciativa de Integração da Infraestrutura Regional SulAmericana $^{17}$ (IIRSA-COSIPLAN). Esta iniciativa se refere a investimentos na construção e no melhoramento de vários objetos técnicos de ligações físicas entre os países sul-americanos ${ }^{18}$, o que afeta também as interações transfronteiriças entre França e Brasil. O Mapa 2, por exemplo, mostra faixas territoriais das Guianas que possuem infraestrutura de integração propostas pela IIRSA-COSIPLAN. Neste caso, embora a Guiana Francesa não esteja em grandes eixos de cooperação regional sulamericana, como na Organização do Tratado de Cooperação Amazônico (OTCA) e também na iniciativa IIRSA-COSIPLAN, ela está pouco a pouco construindo ações de inserção regional com seus vizinhos físicos a partir de ações como o POAmazônia/PCIA (GRANGER, 2012; 2016; SILVA, 2013b; SILVA et al. 2016). Este Programa, ao propor ações de cooperação transfronteiriça com um território europeu na América do Sul, cria conexões de integração que a OTCA e o IIRSA não contemplaram.

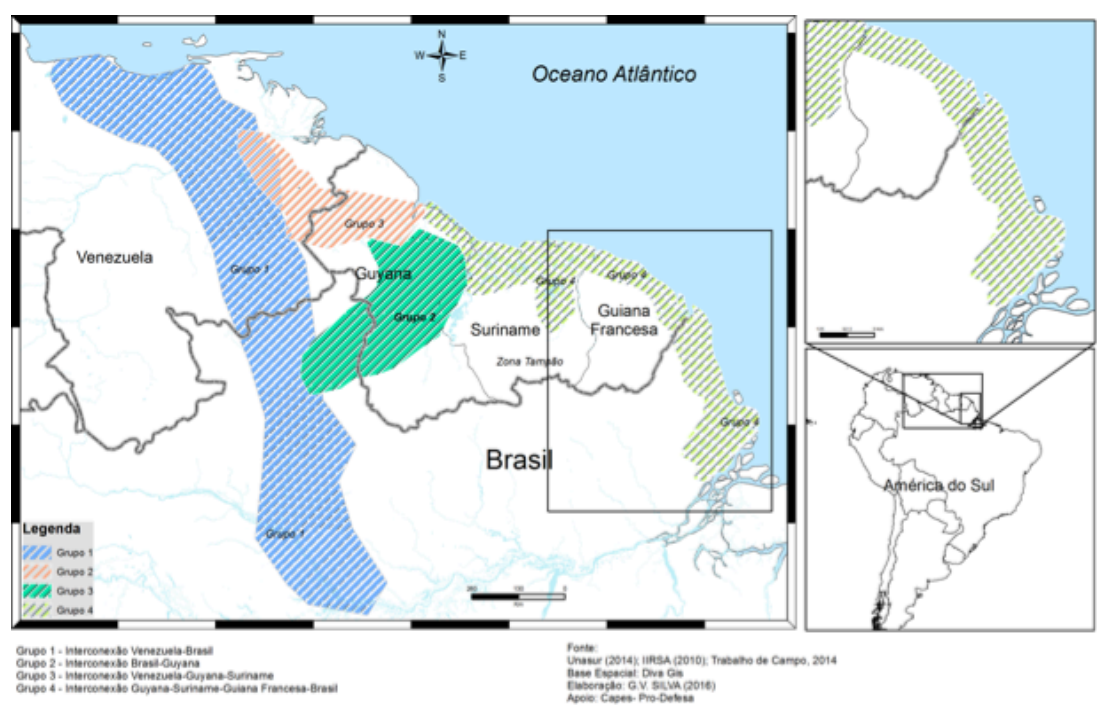

Mapa 2: Franjas-alvo de obras para integração física no escudo das Guianas

\footnotetext{
${ }^{17}$ A IIRSA foi criada em 2000 na $1^{\text {a }}$ Cúpula de Presidentes da América do Sul. A IIRSA se tornou, em 2010, órgão técnico do Conselho de Infraestrutura e Planejamento (Cosiplan) da UNASUL, passando a receber diretrizes políticas dos governos dos países pertencentes ao bloco, de forma a reduzir a influência do trio BID-CAF-Fonplata.

${ }^{18}$ Segundo Padula (2014), diante de seus resultados e da ascensão de novos governos na região nos anos 2000, a IIRSA-COSIPLAN sofreu crescente questionamento e críticas, principalmente por implantar uma visão meramente técnica, não contribuir efetivamente para uma metodologia de seleção de projetos ou de construção de infraestrutura de caráter integracionista regional e, além disso, não conseguir alavancar recursos ou fórmulas inovadoras para o financiamento.
} 
Historicamente, a política orientada para a zona de fronteira franco-brasileira tem uma perspectiva para as autoridades nacionais e outra assimilada pela classe política local. Por exemplo, a cooperação transfronteiriça embalada por temas locais de interesse nacional (pavimentação de vias comunicando os dois países; combate à migração ilegal e circulação transfronteiriça), foi na verdade um pretexto para uma aproximação maior entre os poderes centrais e não esteve de fato em destaque, como mostrou a marginalização dos políticos locais durante os encontros presidenciais na fronteira (Foto 1), sinal de mais um mal-estar entre autoridades locais e nacionais. No encontro dos chefes de Estado em Saint-Georges no ano de 2008 (Foto 1), por exemplo, Luiz Inácio Lula da Silva e Nicolas Sarkozy abordaram principalmente assuntos nacionais (compra dos aviões de caça Rafale; apoio ao Brasil para uma vaga de membro permanente no Conselho de segurança da ONU, etc).

De uma maneira ou de outra, a criação de estratégias de articulações físicoterritoriais e acordos internacionais entre Brasil e França, países de dois continentes diferentes, corroborou a construção de novo usos desafiadores para a fronteira em comum, conferindo-lhes uma nova dimensão geopolítica. Há ainda um desafio 20 anos depois do acordo-quadro que torna ainda mais complexo o entendimento da cooperação transfronteiriça, o desafio identitário analisado a seguir.

\section{Desafios identitários}

A cooperação transfronteiriça expressa também desafios de ordem identitária. A elite local franco-guianense há muito tempo almeja fortalecimento territorial e político a partir de um novo estatuto que alargue os seus poderes, velha reivindicação e, segundo tal elite, condição para a visibilidade de uma identidade amazônica e até sul-americana negada ou desprezada até os dias atuais. De fato, uma característica comum ao Amapá e à Guiana Francesa é a importância da superfície territorial de ambos, cuja jurisdição de boa parte não está a cargo das instituições locais. Por exemplo, faixa de fronteira, parques nacionais e territórios indígenas colocam $72 \%$ do território amapaense na gestão direta do Estado federal, enquanto essa proporção chega a cerca de $90 \%$ na Guiana Francesa, devido à presença da floresta amazônica e do Centro Espacial Europeu instalado em Kourou.

Mas o desejo de fortalecimento da elite local se sobrepunha a uma reivindicação identitária por dois motivos. Em primeira, pela força relacional dos variados grupos indígenas. O limite estabelecido "artificialmente" pelos Estados Nacionais nunca foi uma "barreira" para os índios (Waiampis, Palikurs, Galibis) que na bacia do rio Oiapoque estabelece(ra)m suas práticas espaciais (ver p. ex. GALLOIS, 2005). Esta condição de fortes interações espaciais transfronteiriças de indígenas foi incentivada pelo isolamento geográfico da fronteira franco-brasileira, que perdurou em boa parte 
do século XX. Tal situação, implicou em certa simbiose entre as populações das duas margens do rio Oiapoque.

Em segundo lugar, pela ótica dos políticos. Após um longo período de ignorância e auto isolamento muitas autoridades guianenses manifestaram o desejo de se aproximar do vizinho brasileiro. Depois dos problemas de instabilidade política e econômica vividas pelo Suriname pós-independência (CAVLAK, 2016), a afirmação identitária amazônica e sul-americana franco-guianense, bem como a negação tanto da assimilação como da dependência econômica em relação à Metrópole passavam pelo estabelecimento de relações ainda quase inexistentes com o país-farol da Amazônia e do subcontinente: o Brasil (MAM LAM FOUCK; ANAKESA, 2013).

Isso também seguia a contestação da assimilação decorrente da modificação estatutária de 1946, que fez da Guiana Francesa, antiga colônia, um departamento de Ultramar da República francesa (Ibid. Loc. cit). De fato, i) a distância geográfica em relação à França Hexagonal; ii) a identificação de um meio ambiente amazônico de onde provêm muitos elementos das culturas locais e as influências que circulam, entre gastronômica e musical, dos países vizinhos; iii) a forte presença indígena que quase despareceu das Antilhas; e iv) as rivalidades ancestrais com os francoantilheses, permitiram o surgimento de uma identidade e de uma territorialidade franco-guianense próprias. Antigamente era - com certa frequência - relacionada ao mundo caribenho. A partir dos anos 1980, conforme Desse e Jalabert (2007), desenvolveu-se na Guiana Francesa uma identidade sul-americana permitindo oporse à Metrópole e às ilhas antilhanas, cujo peso político e cultural era considerado forte demais.

Aliás, a presença na Guiana Francesa de várias comunidades oriundas de diferentes países, como do Brasil, mas também Haiti e o Suriname, permitia aos políticos franco-guianenses - pelo menos em teoria - constatar a proximidade cultural que existia, contribuindo com isso para a formação de uma identidade franco-guianense mais próxima da América do Sul. Essa presença estrangeira e a necessidade de ligações com seus países de origem, vizinhos como o Brasil, foram assim destacadas como elemento constitutivo de uma "guianidade" reivindicada pelos políticos em pleno questionamento identitário no seu projeto de sociedade. $\mathrm{O}$ texto abaixo é elucidativo:

En se confrontant à l'autre, à la fois proche et différent, cela oblige à mieux cerner les traits de sa propre identité. En allant à l'extérieur de la Guyane, chacun est automatiquement identifié par l'autre comme "guyanais ». [...] Ainsi va se structurer 
collectivement cette identité guyanaise ${ }^{19}$ (CONGRÈS DES ELUS DE GUYANE, 2009, p.27).

A forte imigração, contudo, também podia apresentar uma ameaça para essa identidade franco-guianense ainda insegura. Por isso, o poder executivo da Guiana Francesa devia justificar essa aproximação em um documento de trabalho do Conselho Regional. Eis que:

En raison d'une mentalité héritée de la colonisation, nous avons souvent perçu nos voisins comme des étrangers avides de nous dévaliser, alors qu'à bien des égards la Guyane gagne à échanger dans des domaines divers avec ses voisins ${ }^{20}$ (CABINET DU CONSEIL RÉGIONAL, 2003, p. 1).

Assim, para o presidente do Conselho regional da Guiana francesa da época, Antoine Karam, essa cooperação permitiria à Guiana francesa partir ao encontro de si-mesma, o franco-guianense sendo ao mesmo tempo um pouco surinamense, um pouco brasileiro (FARINE, 2001).

Esse reposicionamento identitário das autoridades franco-guianenses ajudou muito no estabelecimento de uma cooperação para a qual se precisava de uma visão convergente e colaborativa da/na fronteira, sobretudo depois de três séculos de conflito seguido de isolamento. Porém, fica incontestável que este reposicionamento e o desejo de cooperação da Guiana Francesa com o Brasil devem-se em grande parte à presença migratória clandestina na primeira (GRANGER, 2016). Mas o receio popular de uma "invasão" populacional não assimilável, compartilhada por grande parte da classe política franco-guianense, em contraposição ao desejo de fortalecer a cooperação transfronteiriça, é visível nas contradições dessa nova territorialidade transfronteiriça ainda fragilizada (POLICE, 2010). Em todo caso, mesmo que o Estado francês esteja na base institucional da aproximação francoguiano-brasileira, os franco-guianenses, maiores interessados e que tiveram a iniciativa, aproveitaram o momento para concretizar um desejo antigo de maior autonomia política e de integração regional. Com efeito, entre vontade de afirmação política e identitária de um lado e desejo de proteção no quadro nacional do outro, a cooperação transfronteiriça com o Brasil ilustra todas as contradições do Ultramar francês na América do Sul, sendo esta a chave do desafio identitário.

\footnotetext{
19 “Confrontando-se uma ao outro, ao mesmo tempo próximo e diferente, isso obriga a definir os traços da sua própria identidade. Indo para o exterior da Guiana Francesa, cada um é automaticamente identificado pelo outro como "franco-guianense" [...] Assim vai estruturar-se coletivamente essa identidade francoguianense".

20 "Pelo fato de uma mentalidade herdada da colonização, frequentemente percebemos os nossos vizinhos como estrangeiros ávidos por nos roubar, enquanto por muitas razões a Guiana francesa ganharia em trocar em diversos assuntos com seus vizinhos".
} 


\section{Conclusão}

A cooperação transfronteiriça com o Brasil, como dito no parágrafo anterior, ilustra uma plêiade de contradições da Guiana Francesa em seu ambiente regional. Com a aproximação entre França e Brasil para ações multitemáticas na fronteira que compartilham após a publicação do acordo-quadro de 1996, uma série de desafios apareceram nos últimos 20 anos. Embora tais desafios sejam entrecruzados foi necessário estabelecer grandes eixos analíticos de modo a tornar mais elucidativas as reflexões no presente texto.

Do ponto de vista institucional, primeiro grande eixo tratado no texto, é possível concluir que ainda há a necessidade de um amadurecimento considerável para o fortalecimento da cooperação. Percebem-se baixos critérios de eficácia, eficiência e efetividade nas ações dos gestores. Além disso, o estabelecimento de marcos jurídicos aceitos pelo Brasil, país sul-americano, e pela França, país europeu, é de fato um desafio que sempre estará presente nesta cooperação. Outros, de menor complexidade, mas igualmente representativos, como estruturas administrativas sólidas, maior envolvimento de movimentos sociais e menos políticas top-down são desafios que precisam de amadurecimento também.

No aspecto socioeconômico, segundo grande eixo, destacamos duas questões: em primeiro lugar, a geografia do comércio transfronteiriço, rico em fluxos que transbordam o limite fronteiriço, mas que carecem de um sistema de engenharia eficiente, o que implica em preços elevados para produtos lá comercializados. A inauguração da ponte binacional sobre o rio Oiapoque estabelecerá uma nova fase na geografia econômica e política da fronteira, reordenando espaços de compravenda, ampliando a especulação imobiliária, redefinindo atores envolvidos e criando novos espaços para o capital. $\mathrm{O}$ atraso na abertura desta ponte ilustra toda a complexidade por que passa tal cooperação. $\mathrm{O}$ atraso absorve se não tudo, mas boa parte dos desafios explicitados no texto. Aliás, a abertura parcial e provisória prevista para 2017 só envolverá pedestres e automóveis, os problemas dos transportes de carga e coletivos ainda carecerão de solução, em razão principalmente das diferenças de normas e de seguros entre o Brasil e a UE.

A Guiana Francesa, território de imigração no contexto regional, frequentemente apresenta deliberações para conter a migração ilegal pelo Brasil. Além dos brasileiros se deslocarem para oportunidades de emprego em solo francês-guianês, há ainda o agravante do deslocamento para áreas ilegais de garimpo aurífero na Guiana Francesa, uma questão sensível e desafiadora para os rumos da cooperação transfronteiriça entre França e Brasil. É fato que as situações socioeconômicas muito diferentes fazem dessa cooperação transfronteiriça um exemplo único de cooperação "Norte-Sul", já que envolve uma região pertencendo à UE com salários e leis trabalhistas franceses mas "ultraperiférica", e um estado ainda bastante pobre e também periférico do Brasil. Há ainda outro problema, custos de produção altos na 
Guiana Francesa e na Europa que fazem com que os produtos brasileiros sejam bem mais baratos que os franco-guianenses (agro-industriais como sucos ou laticínios) ou europeus. Este é um receio da classe empresarial franco-guianense, em razão da maior competitividade brasileira na zona de fronteira, explica o medo de uma concorrência nos transportes por exemplo, que atrasa a abertura da ponte para caminhões e ônibus. Por este motivo, pouca efetividade ocorreu até hoje em matéria de circulação de mercadorias.

As diretrizes estratégicas voltadas para a convergência de interesses nacionais e internacionais representantes do eixo geopolítico foi o terceiro desafio tratado. As relações estabelecidas por cada país em seus territórios vizinhos é diferente, em que pese as variadas semelhanças entre eles em termos de população, meio ambiente, geografia física, etc. Desde os primeiros estágios da fundação da União Europeia, a França investe no desenvolvimento de políticas públicas aplicadas às fronteiras francesas em consonância com as diretrizes gerais do bloco, o que afeta diretamente a Guiana Francesa. No Brasil, por outro lado, a cooperação nas áreas de fronteira tem sido um processo lento e diferenciado caso-a-caso, tendo em vista a sua extensão territorial, o número de países envolvidos, a instabilidade política e a ausência de interesses relativamente fortes que se conjuguem e se constituam em ações práticas e harmonizadas para o desenvolvimento regional das áreas de fronteira.

Aliás, o estatuto francês e europeu freia o fortalecimento da integração regional transoceânica. Por exemplo, a Guiana Francesa não pode participar de maneira próativa de organismos continentais como OTCA e UNASUL, as quais permitiriam uma cooperação institucionalizada com os blocos regionais da América do Sul. Por outro lado, esta condição franco-guianense promove: financiamentos nacionais e europeus; leis trabalhistas e sociais melhores que a dos países vizinhos; padrão de vida entre os maiores do continente, entre outros.

A questão identitária, quarto e último grande eixo norteador do artigo, é a mais difícil e complexa de se perceber, já que é a mais subjetiva de nossas argumentações sobre os desafios da cooperação transfronteiriça. Por muito tempo houve um distanciamento identitário na zona de fronteira franco-brasileira. Talvez a linha de corte realista das relações internacionais, duradora ao longo do século XX, principalmente nos primeiros 60 anos, tenha contribuído para sensações de invasão e anexação territorial, pensamento este fecundo na Guiana Francesa por muito tempo. Alguns políticos franco-guianenses, refletindo sobre a opinião de boa parte da população local, temem essa cooperação com o Brasil, por acharem a economia e a população da Guiana Francesa fracas demais para concorrer com o tecido produtivo brasileiro (POLICE, 2010). Outra preocupação de muitos franco-guianenses é que essa cooperação não ligará a Guiana Francesa ao Brasil produtivo e representativo, mas aos estados que pouca importância tiveram para os franco-guianenses - Amapá 
e do Pará. Em contrapartida, fornecerá ao Brasil uma saída terrestre estratégica para a América do Sul e Caribe.

Os fluxos migratórios alteraram o frágil equilíbrio étnico da Guiana Francesa, tornando a parte "crioula" (nativa) minoritária. Além deste aspecto, a população pede reforço de suas fronteiras, o que vai na direção contrária das propostas de cooperação. A construção da ponte sobre o rio Oiapoque e a ligação terrestre entre Caiena e a fronteira brasileira, finalizada em 2003, implicará no aumento da repressão contra brasileiros em situação irregular na Guiana Francesa. A cooperação regional com o Brasil, contudo, pode ajudar à constituição de uma identidade amazônica e sul-americana guianense em pleno questionamento identitário, como permitiu uma autonomização melhor do poder regional franco-guianense: os fundos comunitários europeus agora vão diretamente para o governo estadual, velha reivindicação local, sem transitar, como antes, pela escala nacional.

Diversos outros desafios ainda carecem de atenção e reflexão. Temas voltados para o meio ambiente, segurança internacional e saúde são alguns destes que precisam ser avaliados. São eixos igualmente complexos aos aqui tratados e cujo comportamento e ações para a zona de fronteira também esbarram em uma série de dificuldades para avanço, marcas de ações ineficazes e estruturas ainda muito frágeis para avanços significativos nas propostas colocadas em questão, sinais de uma cooperação regional carente, ainda, de maturidade institucional.

\section{Referências:}

ARAÚJO JORGE, A. G. (1999) Rio Branco e as fronteiras do Brasil (uma introdução às obras do Barão do Rio Branco). Brasília: Senado Federal, 1999. (Coleção Brasil 500 anos).

BOUDOUX D'HAUTEFEUILLE, Madeleine (2012) Entre marge et interface, recompositions territoriales à la frontière franco-brésilienne (Guyane/Amapá). Tese de doutorado em Geografia, Université des Antilles et de la Guyane.

BRASIL (2005) Proposta de reestruturação do Programa de Desenvolvimento da Faixa de Fronteira. Secretaria de Programas Regionais, Programa de Desenvolvimento da Faixa de Fronteira. Brasília. Disponível em : www.integracao.gov.br/publicacoes. Acesso em 20 ago. 2016.

- (2016) Segurança Pública nas Fronteiras: Diagnóstico Socioeconômico e Demográco. Estratégia Nacional de Segurança Pública nas Fronteiras (ENAFRON) / organização, Alex Jorge das Neves et al. - Brasília: Ministério da Justiça e Cidadania, Secretaria Nacional de Segurança Pública.

CABINET DU CONSEIL REGIONAL (2003). La coopération régionale GuyaneAmapá, historique, Cayenne.

CARAMELO, S. (2007) União Européia, Fronteira e Território. Porto: Campo das Letras. 
CAVLAK, Iuri. (2016) Breve História do Suriname. 1. ed. Macapá / Rio de Janeiro: Editora da Unifap / Autografia.

COMMISSION EUROPEENNE. (2015) La coopération territoriale en Europe, une perspective historique. Union Européenne, Direction générale de la Politique régionale et urbaine.

Disponível

em :

http://ec.europa.eu/regional policy/fr/information/publications/brochures/2015/territori al-cooperation-in-europe-a-historical-perspective. Acesso em 20 ago. 2016.

CONGRES DES ELUS DE GUYANE (2009). Fondements du Projet de société, annexe à la résolution adoptée $n^{\circ} 7$. Séance du 2 septembre 2009, mairie de RémireMontjoly. Cayenne. Disponível em : https://documentation.outremer.gouv.fr/Record.htm?idlist=1\&record=19102715124919209979. Acesso em 20 ago. 2016.

DESSE Michel ; JALABERT Laurent. (2007) Les départements français d'Amérique : assimilation, dépendance, et crise identitaire de 1945 à nos jours. In TAGLIONI e THEODAT (org.). Coopération et intégration, perspectives panaméricaines, Paris: L'Harmattan, p. 165-183.

FARINE, F. (2001) Du Brésil à la Guyane : la route des pionniers. Antilla, Fort-deFrance, Martinica, 18 janvier.

GALLOIS, Dominique T. (Org.). (2005) Redes de relações nas Guianas. São Paulo: Humanitas: Fapesp.

GRANGER, Stéphane (2008) “Guiana Francesa : um território europeu e caribenho em via de sul-americanização?" Confins, revista franco-brasileira de geografia, $n^{\circ} 4$. Disponível em : http://confins.revues.org/5003. Acesso em 20 ago. 2016.

. (2012) La Guyane et le Brésil, ou la quête d'intégration continentale d'un département français d'Amérique, Tese de doutorado em geografia, Paris 3 (IHEAL). . (2016) «Intégrations régionales et diversification des flux migratoires dans les mondes caribéen et amazonien: la Guyane entre ouverture et isolement », in: COLLOMB Gérard e MAM LAM FOUCK Serge (dir.). La Guyane entre Surinam et Brésil : mobilités, ethnicités, diversité culturelle. Matoury: Ibis Rouge, p. 25-47.

HEINONEN, Hannu. Regional Integration and the State: The Changing Nature of Sovereignty in Southern Africa and Europe. Doctoral dissertation. University of Helsinki, Faculty of Social Sciences, Institute of Development Studies, June 2006. Disponível em : https://helda.helsinki.fi/bitstream/handle/10138/21770/regional.pdf?sequence=2 . Acesso em 20 ago. 2016.

IIRSA. (2010) Agenda de Implementação Consensuada 2005-2010: 31 projetos estratégicos para América do Sul. Relatório de avaliação. Disponível em: www.iirsa.org. Acesso em 20 ago. 2016.

INSEE. (2011a) Amapá-Guiana Francesa: Melhor estruturar os territórios para intensificar os intercâmbios. Guiana Francesa: PRIM.

INSEE. (2011b) Guyane : un développement sous contraintes. Guiana Francesa: PRIM. 
INSEE. (2012) Panorama de la population immigrée en Guyane. INSEE AntillesGuyane.

MAM LAM FOUCK Serge, e ANAKESA, Apollinaire. (2013) Nouvelle histoire de la Guyane. Matoury: Ibis rouge, $384 \mathrm{p}$.

PADULA, Rafael. (2014) Da IIRSA ao COSIPLAN da UNASUL: A integração de infraestrutura na América do Sul nos anos 2000 e suas perspectivas de mudança. In: DESIDERÁ NETO, Walter Antonio (Org). O Brasil e novas dimensões da Integração Regional. Rio de Janeiro: Ipea.

POLICE Gérard. (2010) Eudorado. Le discours brésilien sur la Guyane française. Matoury: Ibis Rouge.

PORTO, Jadson Luis Rebelo. (2003) Amapá: Principais Transformações Econômicas e Institucionais (1943-2000). Macapá: SETEC.

PORTO, Jadson Luis Rebelo. (2005) Transformações espaciais no Amapá. Reflexos de uma economia em construção. In: PORTO, Jadson Luis Rebelo et al. Amapá : Aspectos de uma Geografia em Construção. Macapá : Jadson Porto.

REIS, Arthur César Ferreira. (1993) Limites e demarcações na Amazônia brasileira. Belém, Secult, 1993.

SILVA, Gutemberg de Vilhena; RÜCKERT, Aldomar Arnaldo. (2009) A Fronteira Brasil-França: mudança de usos político-territoriais na fronteira entre Amapá (BR) e Guiana Francesa (FR). Confins, n.7. Disponível em http://confins.revues.org/6040. Acesso em 20 ago. 2016.

SILVA, Gutemberg de Vilhena. (2013a) Usos contemporâneos da fronteira francobrasileira: entre os ditames globais e a articulação local / Gutemberg de Vilhena Silva. - Macapá : UNIFAP.

SILVA, Gutemberg de Vilhena. (2013b). A cooperação transfronteiriça entre Brasile França: ensaios e expectativas neste século XXI (Tese de Doutorado). Universidade Federal do Rio de Janeiro (UFRJ).

SILVA, Gutemberg de Vilhena, et al. (2016) «La géopolitique de l'Union Européenne pour les régions ultrapériphériques : ", Confins [En ligne], 26|2016, on line o 03 de março 2016, consultado o 14 de maio de 2016. Disponível em: http://confins.revues.org/10658. Acesso em 20 ago. 2016.

(2016) France-Brazil Cross-border Cooperation Strategies: Experiences and Perspectives on Migration and Trade. Journal of Borderlands Studies. Disponível em : http://dx.doi.org/10.1080/08865655.2016.1197788. Acesso em 20 ago. 2016.

TAGLIONI, François, CRUSE Romain. (2011) Le Suriname : une île caribéenne comme les autres ? In: CRUSE, Romain e RHINEY, Kevon(dir.), Caribbean Atlas. Disponível em: http:/www.atlas-caraibe.fr/thematiques/qu-est-ce-que-la-caraibe/lesuriname-une-ile-caribeenne-comme-les-autres.html Consultado o 07.04.2012. Acesso em 20 ago. 2016.

UNASUR. (2014) Agenda de Proyectos Prioritarios de Integración. Informe de Avance. V Reunión Ordinaria del COSIPLAN Montevideo, Uruguay, 4 de diciembre 
UNION EUROPENNE. (2002) Avis du comité des Régions sur les «stratégies pour la promotion de la coopération transfrontalière et internationale dans une Europe élargie - un document fondamental et d'orientation pour l'avenir ». Disponível em : http://eur-lex.europa.eu/legal-content/FR/TXT/?uri=CELEX\%3A52000AR0180. Acesso em 20 ago. 2016.

Data de submissão: 07/09/2016.

Data de aceite: 22/12/2016. 